ARTICLE

DOI: $10.1038 / \mathrm{s} 41467-017-01672-4$

OPEN

\title{
Atomically-precise colloidal nanoparticles of cerium dioxide
}

\author{
Kylie J. Mitchell', Khalil A. Abboud ${ }^{1} \&$ George Christou (i) $^{1}$
}

Synthesis of truly monodisperse nanoparticles and their structural characterization to atomic precision are important challenges in nanoscience. Success has recently been achieved for metal nanoparticles, particularly $\mathrm{Au}$, with diameters up to $3 \mathrm{~nm}$, the size regime referred to as nanoclusters. In contrast, families of atomically precise metal oxide nanoparticles are currently lacking, but would have a major impact since metal oxides are of widespread importance for their magnetic, catalytic and other properties. One such material is colloidal $\mathrm{CeO}_{2}$ (ceria), whose applications include catalysis, new energy technologies, photochemistry, and medicine, among others. Here we report a family of atomically precise ceria nanoclusters with ultra-small dimensions up to $\sim 1.6 \mathrm{~nm}$ ( $\sim 100$ core atoms). X-ray crystallography confirms they have the fluorite structure of bulk $\mathrm{CeO}_{2}$, and identifies surface features, $\mathrm{H}^{+}$binding sites, $\mathrm{Ce}^{3+}$ locations, and $\mathrm{O}$ vacancies on (100) facets. Monodisperse ceria nanoclusters now permit investigation of their properties as a function of exact size, surface morphology, and $\mathrm{Ce}^{3+}: \mathrm{Ce}^{4+}$ composition.

\footnotetext{
${ }^{1}$ Department of Chemistry, University of Florida, Gainesville, FL 32611-7200, USA. Correspondence and requests for materials should be addressed to G.C. (email: christou@chem.ufl.edu)
} 
S ince its introduction in 1976 as an oxygen-storage component to ensure the efficient activity of the noble metals used in three-way catalysis in automobile exhausts ${ }^{1-3}$, cerium (IV) dioxide $\left(\mathrm{CeO}_{2}\right.$, ceria) has become of considerable utility as a catalyst or co-catalyst in industrial, petrochemical and environmental processes ${ }^{2-7}$. In addition, $\mathrm{CeO}_{2}$-containing materials are often used in oxide fuel cells ${ }^{8}$, precision polishing materials ${ }^{9}, 10$, UV filters ${ }^{10}$, corrosion prevention ${ }^{11}$, and other applications ${ }^{1,12,13}$. This widespread use of $\mathrm{Ce}$ is partially due to its significant abundance $(0.0046 \%$ by weight of the Earth's crust) and its $\mathrm{Ce}^{3+} / \mathrm{Ce}^{4+}$ redox couple, which is crucial to many applications by facilitating the formation of $\mathrm{CeO}_{2-x}$, containing highly reactive defect sites comprising $\mathrm{O}$ vacancies and attendant $\mathrm{Ce}^{3+}$ ions ${ }^{1,12,14}$. Ceria can thus act as an efficient oxygen buffer, assisted by oxygen mobility within its layered fluorite structure. In fact, bulk ceria naturally contains relatively few $\mathrm{Ce}^{3+} / \mathrm{O}$-vacancy defect sites at ambient temperatures, but their number increases at higher temperatures where $\mathrm{Ce}^{4+}$ reduction and oxygen release are favoured. Catalysis by bulk ceria is therefore normally carried out at temperatures $>450{ }^{\circ} \mathrm{C}$.

In the last decade, interest in ceria nanoparticles (CNPs) has seen explosive growth due to their much greater reactivity and increased catalytic efficiencies at lower temperatures 9,12 . Significant CNP activity at or near room temperature has also been established ${ }^{15}$, as has facet-dependent reactivity ${ }^{12,16}$. For example, appreciable oxygen storage capacity is observed at $150^{\circ} \mathrm{C}$ on the cubic (100) face of nanoceria crystals, which is $\sim 250^{\circ} \mathrm{C}$ lower than for irregularly shaped nanoceria or the bulk material ${ }^{17}$. CNPs are also under investigation as photovoltaic materials in solar cells whereas bulk $\mathrm{CeO}_{2}$ has no photovoltaic response $^{18}$. Using CNPs instead of a cerium oxide support increases by two orders of magnitude the activity of a Au catalyst for the selective oxidation of $\mathrm{CO}^{19}$. In addition, the higher reactivity of CNPs at ambient temperatures is permitting many important biomedical applications to be developed, such as scavenging of reactive oxygen species (ROS) $)^{12,20-22}$. The CNP activity and toxicity to living tissue clearly depend on particle size and surface composition (e.g., $\mathrm{Ce}^{3+} / \mathrm{Ce}^{4+}$ ratios), but as is normally the case in all areas of nanoparticle science, the problems of polydispersity, agglomeration, and surface variations have plagued detailed study of these parameters ${ }^{10,23,24}$. For CNPs, it is particularly challenging to determine the concentration and locations of $\mathrm{Ce}^{3+}$, attendant $\mathrm{O}$ vacancies, and protonated $\mathrm{O}$ (i.e., $\mathrm{OH}^{-}, \mathrm{H}_{2} \mathrm{O}$ ) species on the surface, and the relationship a

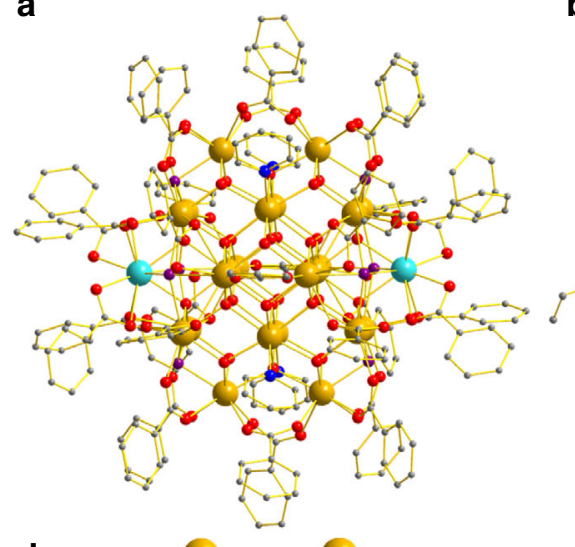

d

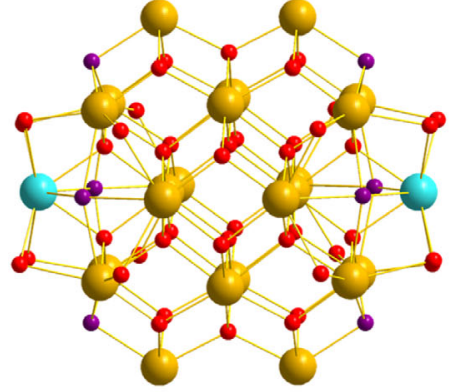

g

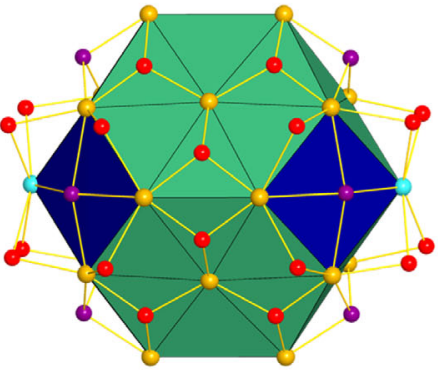

b

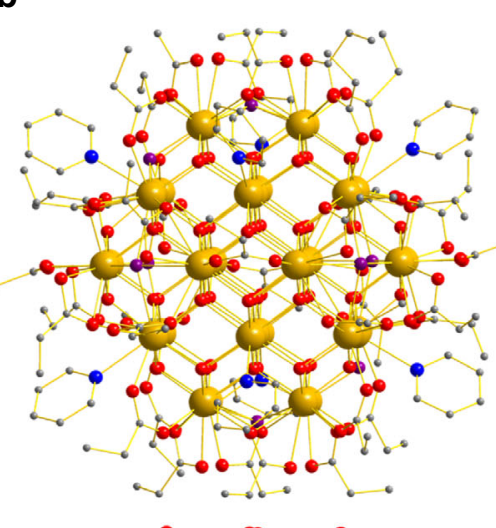

e

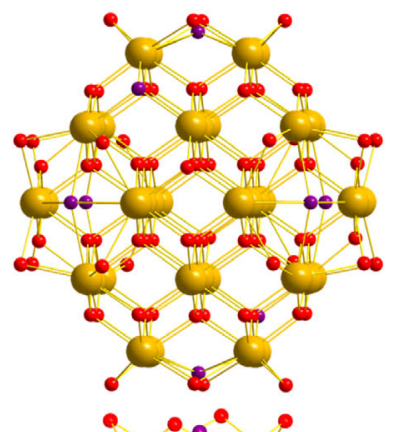

h

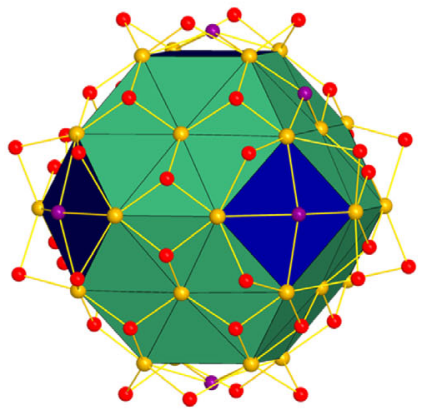

C

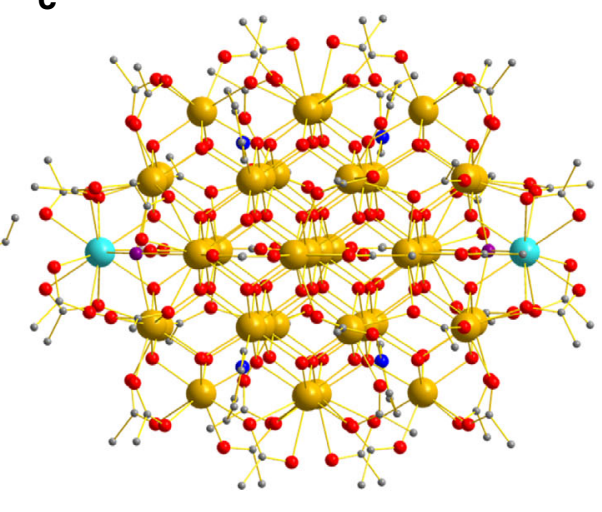

f

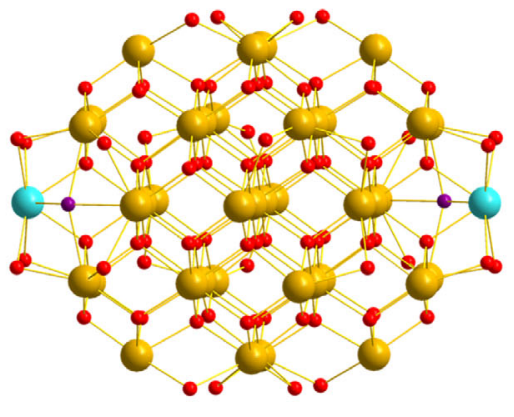

i

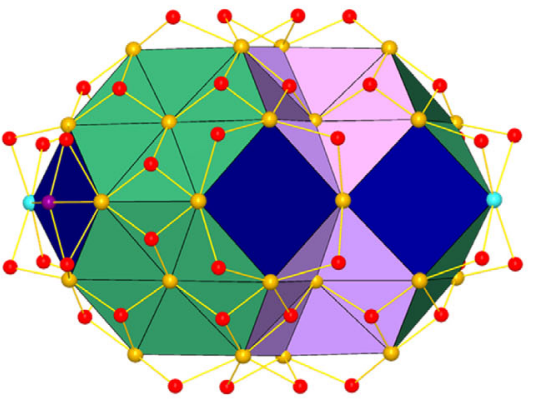

Fig. 1 Structures of ceria nanoclusters. a-c show the complete structures of $\mathbf{1}\left(\mathrm{Ce}_{24}\right), \mathbf{2}\left(\mathrm{Ce}_{38}\right)$, and $\mathbf{3 a}\left(\mathrm{Ce}_{40}\right)$, respectively. $\mathrm{H}$ atoms have been omitted for clarity. Atom sizes of $\mathrm{C}, \mathrm{N}$, and $\mathrm{O}$ are made small to emphasize Ce locations. Colour code: $\mathrm{Ce}^{\mathrm{IV}}$ gold, Ce $\mathrm{e}^{\mathrm{Ill}}$ sky blue, $\mathrm{O}$ red, $\mathrm{N}$ blue, $\mathrm{C}$ grey. $\mathbf{d}-\mathbf{f}$ show their $\mathrm{Ce} / \mathrm{O}$ cores from the same viewpoint (including carboxylate $\mathrm{O}$ atoms that are bridging) using the same colour code except that protonated $\mathrm{O}$ atoms (i.e., $\mathrm{OH}^{-}$ions) are indicated in purple. $\mathbf{g}$-i show the cores again, from approximately the same viewpoint but with surface facets colour-coded: (100) facets are blue; (110) facets are violet; (111) facets are green. Only carboxylate $\mathrm{O}$ atoms that are bridging are included 
a

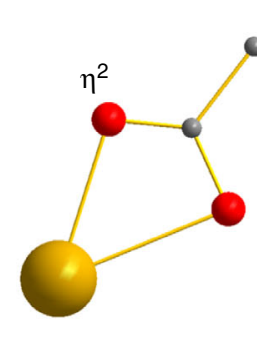

b

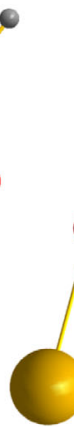<smiles>CCC</smiles>

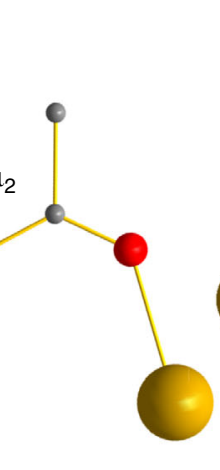

C

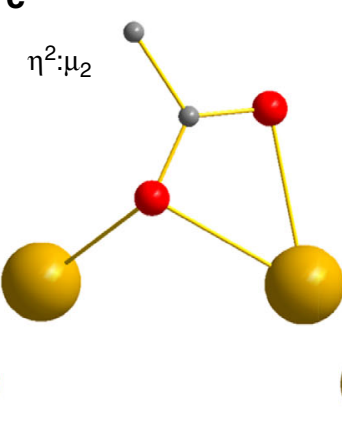

d

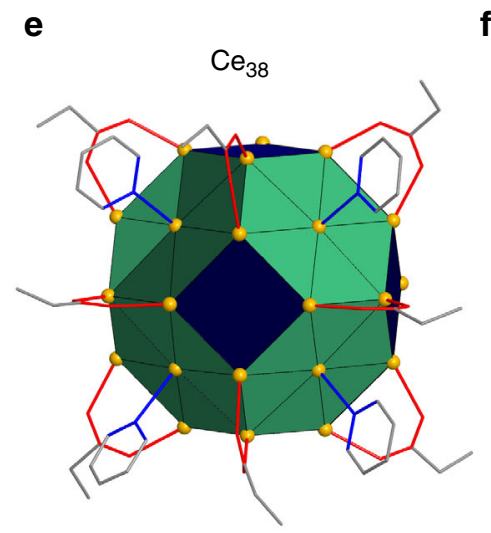

f

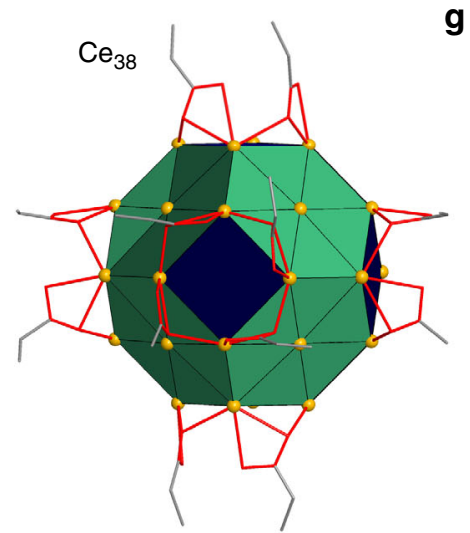

$\mathbf{g}$

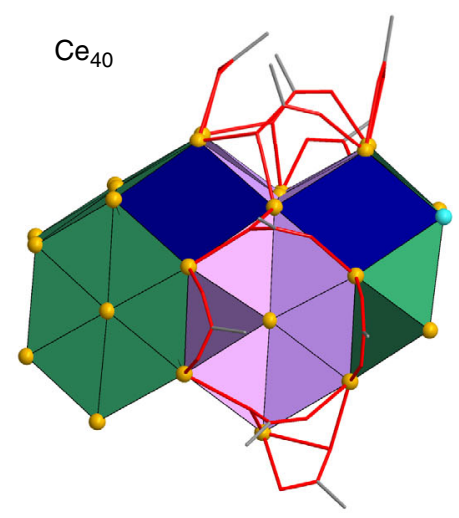

Fig. 2 Ligand binding modes on the surface of ceria nanoclusters. The different binding modes of surface carboxylate and pyridine groups in 1-3: a chelating $\left(\eta^{2}\right)$; b $\mu_{2}$-bridging; $\mathbf{c} \eta^{2}$-chelating and $\mu_{2}$-bridging; $\mathbf{d} \mu_{3}$-bridging; $\mathbf{e} \mathrm{Ce}_{38}$ (2) showing terminal pyridines 'capping' (binding to the center of) the (111) hexagons, and $\mu_{2}$-carboxylates bridging edges joining two (111) facets; $\mathbf{f} C \mathrm{Ce}_{38}(\mathbf{2})$ showing $\eta^{2}: \mu_{2}$-carboxylates at edges joining (100) and (111) facets; and $\mathbf{g ~ C e} 40$ (3) showing $\eta^{2}: \mu_{2^{-}}$and $\mu_{3}$-carboxylates on edges of (110) facets, and $\mu_{2}$-carboxylates bridging edges joining (110) and (111) facets. Colour code: $\mathrm{Ce}^{\mathrm{IV}}$ gold, Ce ${ }^{\mathrm{III}}$ sky-blue, O red, N blue, C grey, (100) facets dark blue; (110) facets violet; (111) facets green

between them ${ }^{10}$. A more controlled approach to monodisperse $\mathrm{CeO}_{2}$ nanoclusters and nanoparticles is clearly needed, especially at the ultra-small, sub- $20 \mathrm{~nm}$ sizes that are of growing importance, particularly for biomedical applications.

We now describe development of procedures using simple $\mathrm{Ce}^{4+}$ salts and organic reagents that yield a family of monodisperse ceria nanoclusters of different sizes depending on the carboxylic acid employed. Such an approach was recently accomplished for monodisperse metal nanoclusters, primarily of $\mathrm{Au}$, stabilized by thiolate ligands ${ }^{25,26}$. In our work, the ligands of choice for metal oxide nanoclusters are carboxylates, especially since oleic and similar acids are common surfactants in metal oxide nanoparticle syntheses ${ }^{20,27}$. The solubility and monodisperse nature of the products we obtain allows molecular crystals to be grown, leading to structural characterization of the nanoclusters and their surface features to atomic precision by single-crystal $\mathrm{X}$-ray diffractometry. The nanoclusters are $\left[\mathrm{Ce}_{24} \mathrm{O}_{28}(\mathrm{OH})_{8}\right.$ $\left.\left(\mathrm{PhCO}_{2}\right)_{30}(\mathrm{py})_{4}\right]\left(\mathbf{1} ; \mathrm{Ce}_{24}\right),\left[\mathrm{Ce}_{38} \mathrm{O}_{54}(\mathrm{OH})_{8}\left(\mathrm{EtCO}_{2}\right)_{36}(\mathrm{py})_{8}\right]\left(\mathbf{2} ; \mathrm{Ce}_{38}\right)$ and $\left[\mathrm{Ce}_{40} \mathrm{O}_{56}(\mathrm{OH})_{2}\left(\mathrm{MeCO}_{2}\right)_{44}\left(\mathrm{MeCO}_{2} \mathrm{H}\right)_{2}(\mathrm{py})_{4}\right] /\left[\mathrm{Ce}_{40} \mathrm{O}_{56}(\mathrm{OH})_{2}\right.$ $\left.\left(\mathrm{MeCO}_{2}\right)_{44}(\mathrm{MeCN})_{2}(\text { py })_{4}\right]\left(\mathbf{3 a} / \mathbf{b} ; \mathbf{C e}_{40}\right)$, where py is pyridine. $\mathbf{3 a} / \mathbf{3 b}$ denote the two independent nanoclusters in the asymmetric unit of 3, which differ slightly in the organic ligation. 2 also contains two independent nanoclusters $(\mathbf{2} \mathbf{a} / \mathbf{2} \mathbf{b})$, but they have the same formulation.

\section{Results}

Nanocluster structures. Several pertinent points about the complete structures of 1-3 (Fig. 1a-c) will be summarized to allow for convenient comparisons. They all comprise $\mathrm{Ce}_{x} \mathrm{O}_{y}$ cores (excluding carboxylate $\mathrm{O}$ atoms) with metal $(x)$ and total $(x+y)$ atom counts of $24 / 60,38 / 100$ and $40 / 98$ for $\mathbf{1 - 3}$, respectively, and they exhibit the same fluorite structure as bulk $\mathrm{CeO}_{2}$, i.e., alternating layers of 8-coordinate cubic $\mathrm{Ce}^{4+}$ and 4-coordinate tetrahedral $\mathrm{O}^{2-}$ ions. Some surface $\mathrm{Ce}^{4+}$ ions are 7- or 9-coordinate (vide infra). From the viewpoint of Fig. 1d-f, the cores consist of five Ce layers in an A:B:C:B:A pattern $(1, A=2, B=6, C=8 ; 2, A=4, B=9, C=12 ; 3, A=4, B=10, C$ $=12)$, leading to the $\mathrm{Ce}_{38}$ core of 2 being essentially spherical $(1.12 \times 1.12 \times 1.12 \mathrm{~nm})$ whereas those of $\mathrm{Ce}_{24}(1,0.75 \times 1.10 \times$ $1.10 \mathrm{~nm})$ and $\mathrm{Ce}_{40}(3,1.13 \times 1.13 \times 1.61 \mathrm{~nm})$ are ellipsoidal. The $\mathrm{Ce}_{38}$ can also be described as a 'truncated octahedron', a structure that is one of those recently predicted by DFT studies to be favoured for $\mathrm{Ce}_{x} \mathrm{O}_{y}$ fragments of $\mathrm{CeO}_{2}$ in this size range ${ }^{28}$. 2 contains only $\mathrm{Ce}^{4+}$, but $\mathbf{1}$ and 3 each also contain two 10-coordinate $\mathrm{Ce}^{3+}$ ions at opposite ends of the cores, as suggested by DFT calculations on $\mathrm{Ce}^{3+}$ in $\mathrm{Ce}_{x} \mathrm{O}_{y}$ fragments of $\mathrm{CeO}_{2}{ }^{28,29}$. The $\mathrm{Ce}$ oxidation states were confirmed by bond valence sum (BVS) calculations (Supplementary Table 2) and the detection of $\mathrm{Ce}^{3+}(S=1 / 2)$ EPR spectra for 1 and 3 . The latter were measured on microcrystalline powders at $5 \mathrm{~K}$ (Supplementary Figs. 1 and 2) and are comparable with the few $\mathrm{Ce}^{3+}$ EPR spectra reported for $\mathrm{CeO}_{2}$ nanoparticles or $\mathrm{Ce}^{3+}$ doped into polymeric species $^{30-32}$. Nanoclusters 1-3 are large enough to display multiple facets (Fig. 1g-i), as do CNPs; the different faces for $\mathrm{CeO}_{2}$ and $\mathrm{Ce}_{40}$ are defined in Supplementary Fig. 3. 1 and 2 display only (100) and (111) facets, whereas 3 exhibits these and also (110) facets. Finally, the cores are enveloped within monolayer organic shells of carboxylate and py groups, which exhibit only minor positional disorder in some $\mathrm{C}$ and $\mathrm{O}$ atoms (Fig. 1a-c). 
Table 1 Type of surface ligands in nanoclusters 1-3

\begin{tabular}{llll} 
Type & Binding mode & Found & Surface location \\
\hline $\mathrm{O}^{2-}$ & $\mu_{3}$-bridging & $\mathbf{1 - 3}$ & $(111)$ or $(110) \mathrm{Ce}_{3}$ triangle \\
$\mathrm{OH}^{-}$ & $\mu_{3}$-bridging & $\mathbf{1} \mathbf{2}$ & $(111) \mathrm{Ce}_{3}$ triangle \\
$\mathrm{OH}^{-}$ & $\mu_{4}$-bridging & $\mathbf{1 - 3}$ & Lid on $(100) \mathrm{Ce}_{4}$ square \\
$\mathrm{py}$ & terminal & $\mathbf{1 - 3}$ & Capping of $(111)$ hexagon \\
$\mathrm{MeCN}^{-}$ & terminal & $\mathbf{3 b}$ & Lid on $(100) \mathrm{Ce}_{4}$ square \\
$\mathrm{RCO}_{2}{ }^{-}$ & $\eta_{2^{-} \text {-chelating }}$ & $\mathbf{3}$ & Lid on $(100) \mathrm{Ce}_{4}$ square \\
$\mathrm{RCO}_{2}{ }^{-}$ & $\eta^{2} \mu_{2}$-chel/brid & $\mathbf{1 - 3}$ & $\mathrm{Ce}$ edge joining $(100)(111)$ \\
$\mathrm{RCO}_{2}{ }^{-}$ & $\mu_{2}$-bridging & $\mathbf{3}$ & $\mathrm{Ce}$ edge joining $(110)(111)$ \\
$\mathrm{RCO}_{2}{ }^{-}$ & $\mu_{3}$-bridging & $\mathbf{1 - 3}$ & $\mathrm{Ce}$ edge joining $(111)(111)$ \\
& & $\mathbf{3}$ & $\mathrm{Ce}$ edge joining $(110)(111)$ \\
\end{tabular}

The structural results thus strongly support the description of 1-3 as atomically precise ceria nanoclusters in the ultra-small size range corresponding to the smallest CNPs synthesized to date, and stabilized to agglomeration by the organic monolayers. CNPs at this sub-20 nm size are being heavily targeted for use in various applications, especially in the biomedical field because they show enhanced catalytic activity and regenerative properties ${ }^{21,33,34} \cdot 1-3$ are larger than the few previously known Ce/O molecular species, most of which are $\mathrm{Ce}_{6}$ species ${ }^{35,36}$ and some with tridentate amino-alcohol N,O,O-chelates ${ }^{37}$. It should be noted that the large family of monodisperse, crystalline polyoxometalates, some with very high metal nuclearities and sizes approaching $4 \mathrm{~nm}$, have been known for many decades, but they do not possess the structure of bulk metal oxides and therefore cannot be described as their nanoparticles.

Surface features. X-ray crystallography has allowed definition to atomic resolution of the surfaces, which are crucial to CNP reactivity. The overall question is how the geometry and environments of surface $\mathrm{Ce}$ and $\mathrm{O}$ atoms differ from those of body atoms. Indeed, surface $\mathrm{Ce}^{4+}$ geometries in 1-3 differ markedly from the 8-coordinate cubic of body $\mathrm{Ce}^{4+}$ ions. Even those still 8coordinate are significantly distorted, while many are 9-coordinate and there is even rare 7-coordination for Ce12/Ce22 in $\mathbf{3} \mathbf{a} / \mathbf{3 b}$, respectively; coordination numbers are listed for all Ce atoms in Supplementary Table 2. This variety reflects both the greater degrees of freedom at the surface and at the carboxylate ligation. Nevertheless, all body and surface Ce atoms are essentially at the positions they would occupy in bulk $\mathrm{CeO}_{2}$, as shown by the overlays in Supplementary Fig. 4. The larger nanoclusters $\mathrm{Ce}_{38}$ (2) and $\mathrm{Ce}_{40}$ (3) show very little deviation of $\mathrm{Ce}$ and $\mathrm{O}$ atoms from their positions in bulk ceria; the smallest, $\mathrm{Ce}_{24}$ (1), appears more pliable by showing greater deviation, but it is still small. Thus, the $\mathrm{Ce}_{x} \mathrm{O}_{y}$ cores of $\mathbf{1 - 3}$ really can be described as fragments of bulk ceria, stabilized/passivated by the monolayer of carboxylate and pyridine ligands.

There are four types of carboxylate binding in 1-3 (Fig. 2a-d): chelating $\left(\eta^{2}\right)$ and three doubly or triply bridging modes, allowing for flexibility and versatility in binding to one, two, or V-shaped sets of three surface Ce ions. The carboxylates can thus accommodate the multi-faceted surface structure, including points of high curvature (Supplementary Fig. 5), with terminal py groups completing ligation where necessary. Both types of $\mu_{2}$-carboxylates occur in all three nanoclusters and bridge $\mathrm{Ce}_{2}$ edges joining two facets, one of which is always a (111) facet (Table 1 and Fig. 2e-g). Interestingly, the $\eta^{2}: \mu_{2}$ mode is found only at $(100)(111)$ and $(110)(111)$ edges, whereas the $\mu_{2}$ mode is found only at $(111)(111)$ and $(110)(111)$ edges. In contrast, $\mu_{3}$-carboxylates occur only in 3 , bridging a V-shaped edge of the (110) facets. The $\eta^{2}$-chelating mode is also only found in $\mathbf{3}$, always bound to one Ce of a (100) $\mathrm{Ce}_{4}$ square (vide infra). Terminal py ligands occur in all three nanoclusters, always 'capping' a (111) hexagon, i.e., attached to its central Ce (Fig. 2e). The two independent $\mathrm{Ce}_{38}$ nanoclusters in $\mathbf{2}$ are identical in formula and structure, but the two $\mathrm{Ce}_{40}$ units in 3 provide the benefit of slightly differing organic monolayer shells, revealing one way the latter can vary for a given nanocluster core. Thus, the chelating carboxylates (Fig. 2a) on two $\mathrm{Ce}^{4+}$ ions (Ce9) in $\mathbf{3 a}$ are each replaced by a terminal $\mathrm{MeCN}$ (on $\mathrm{Ce} 32$ ) in $\mathbf{3 b}$, converting 9-coordinate $\mathrm{Ce} 9$ into 8-coordinate $\mathrm{Ce} 32$.

There are two distinct Ce surface subunits in 1-3 resulting from the fluorite structure, $\mathrm{Ce}_{3}$ triangles and $\mathrm{Ce}_{4}$ squares, and these will be described in turn. $\mathrm{Ce}_{3}$ triangles are very common surface units in (111) and (110) facets and are bridged primarily by pyramidal $\mu_{3^{-}}$ $\mathrm{O}^{2-}$ ions (Table 1), from tetrahedral body $\mathrm{O}^{2-}$ ions now binding one less Ce. Some in $\mathbf{1}$ and 2 are instead bridged by $\mu_{3}-\mathrm{OH}^{-}$ions (Fig. 3a): The four in $\mathbf{1}$ are obvious from their $\mathrm{O}-\mathrm{H} \cdots \mathrm{N}$ hydrogen bonding to lattice py molecules $(\mathrm{O} \cdots \mathrm{N}=2.7-2.9 \AA)$, which thus anchors the $\mathrm{H}^{+}$on $\mathrm{O} 15$ and $\mathrm{O} 16$ and gives the expected $\mathrm{O}$ BVS of 1.21 (Supplementary Table 3). In contrast, the two $\mu_{3}-\mathrm{OH}^{-}$in 2 are disordered since there is no reason for $\mathrm{H}^{+}$to favour particular $\mu_{3^{-}}$ $\mathrm{O}^{2-}$ ions when so many are essentially equivalent. Slightly lowered BVS values (1.52-1.72) for the four $\mu_{3}-\mathrm{O}^{2-}$ ions at $\mathrm{O} 18 / \mathrm{O} 39$ and the four at $\mathrm{O} 49 / \mathrm{O} 60$ in $\mathbf{2 a}$ and $\mathbf{2} \mathbf{b}$, respectively (Supplementary Table 4 ), suggest that the $2 \mathrm{H}^{+}$are randomly distributed primarily among these positions to give partial $\mu_{3}-\mathrm{OH}^{-}$occupancies.

In body $\mathrm{Ce}_{4}$ squares, each edge is oxide-bridged, but at the surface the edges are carboxylate-bridged. These are the (100) facets (Fig. 1g-i) and occur in three slightly different forms. The six separated $\mathrm{Ce}^{4+}{ }_{4}$ squares in 2 (Fig. 3b), the two $\mathrm{Ce}^{4+}{ }_{3} \mathrm{Ce}^{3+} \mathrm{Ce}^{4+}{ }_{3}$ $\mathrm{V}$-shaped double-squares fused at a $\mathrm{Ce}^{3+}$ corner in $\mathbf{1}$ (Fig. $3 \mathrm{f}$ ), and two $\mathrm{Ce}^{4+}{ }_{3} \mathrm{Ce}^{3+}$ squares in 3 (Fig. $3 \mathrm{c}$ ) are all bridged by a $\mu_{4}-\mathrm{OH}^{-}$ ion with rare tetragonal pyramidal geometry (the $\mathrm{O}$ is $0.7-0.8 \AA$ above the $\mathrm{Ce}_{4}$ plane). All $\mu_{4}-\mathrm{OH}^{-}$ions have similar O BVS values of 0.52-0.71 (Supplementary Tables 3-5), intermediate between those of $\mathrm{OH}^{-}$and $\mathrm{H}_{2} \mathrm{O}$. In $\mathbf{1}$ (but not 2 or 3), the $\mu_{4}-\mathrm{OH}^{-}$protons (H12 and H14) were observed in difference Fourier maps, confirming them (and by extension those in 2 and 3 ) to be $\mathrm{OH}^{-}$, not $\mathrm{H}_{2} \mathrm{O}$. The $\mathrm{Ce}^{4+} . . \mathrm{OH}^{-}$and $\mathrm{Ce}^{3+} . . \mathrm{OH}^{-}$distances are extremely long (2.7-3.0 ̊; Supplementary Table 7) and suggest minimal Ce-O bonding; for comparison, $\mathrm{Ce}^{4+}-\mu_{3}-\mathrm{O}^{2-}=2.2-2.3 \AA$, $\mathrm{Ce}^{4+}-\mu_{4}-\mathrm{O}^{2-}=2.3-2.35 \AA$, and $\mathrm{Ce}^{4+}-\mu_{3}-\mathrm{OH}^{-}=2.3-2.45 \AA$. The very-long $\mathrm{Ce} \cdot \cdot \mu_{4}-\mathrm{OH}^{-}$distances suggest an essentially free $\mathrm{OH}^{-}$ ion acting as a weakly docked 'lid' on the $\mathrm{Ce}_{4}$ surface (and thus rationalizing its small BVS). Space-filling representations (Supplementary Fig. 6) show the $\mathrm{OH}^{-}$to be encapsulated by the surrounding carboxylates and cannot move from its $\mu_{4}$ central position to become more strongly bound $\mu_{2}$ or $\mu_{3}$.

3 also contains planar double-square units (Fig. 3d, e), and these do not contain $\mu_{4}-\mathrm{OH}^{-}$ions. Instead, those in 3a (Fig. 3d) have $\eta^{2}$-carboxylates attached to one Ce that act as lids, tilting inwards so that one $\mathrm{O}$ atom approaches the mid-point of each square; the three resulting Ce..O separations ( 3.0 $\AA$ ) indicate extremely weak contacts (Supplementary Table 8). In $\mathbf{3 b}$, one $\eta^{2}$ carboxylate of each double-square is replaced by an $\mathrm{MeCN}$, as described above, and this again tilts over the center of the square to act as a lid, giving a very unusual bent binding mode. The three resulting $\mathrm{Ce} \cdot \cdot \mathrm{N}$ separations $(>3.0 \AA)$ again indicate only very weak contacts. Interestingly, these planar double squares in 3 are each fused at their $\mathrm{Ce}^{3+}$ corners to the $\mu_{4}-\mathrm{OH}^{-}$-bridged $\mathrm{Ce}^{4+}{ }_{3} \mathrm{Ce}^{3+}$ squares (Fig. 3c) described above, so that 3 contains two asymmetric L-shaped $\left(86.1^{\circ}\right)$ triple squares with the $\mathrm{Ce}^{3+}$ lying at the inner point of the L. For charge balance, 3a must also contain two additional $\mathrm{H}^{+}$. Since the O BVS values indicate they are not on surface $\mu_{3}-\mathrm{O}^{2-}$ ions, we suspected them to be on ligand groups. Indeed, three carboxylate $\mathrm{O}$ atoms 
a

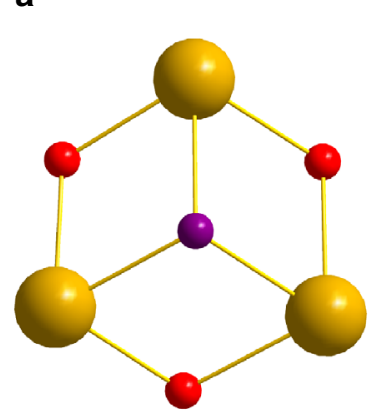

b

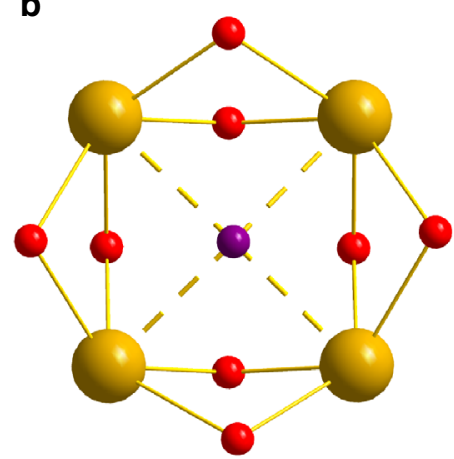

C

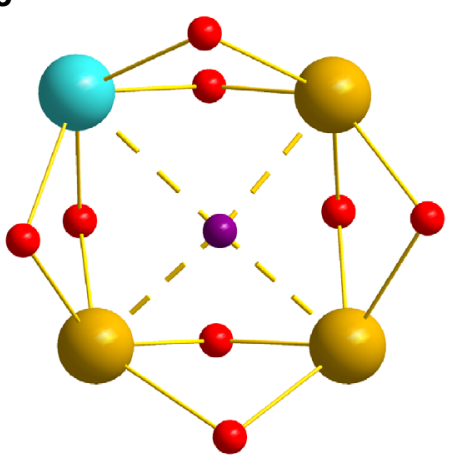

d

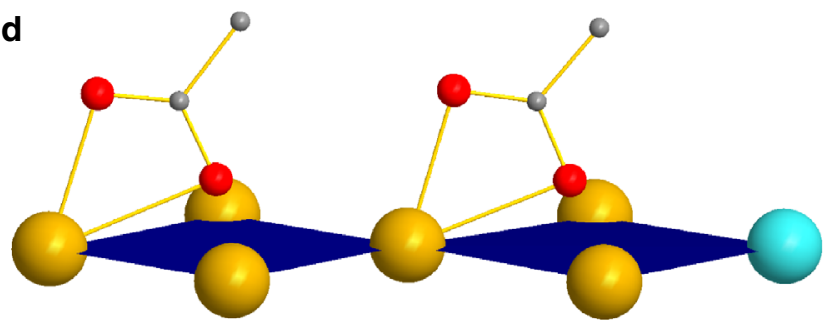

e

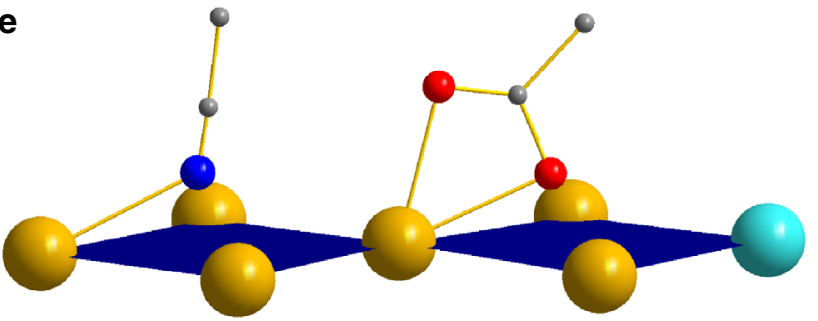

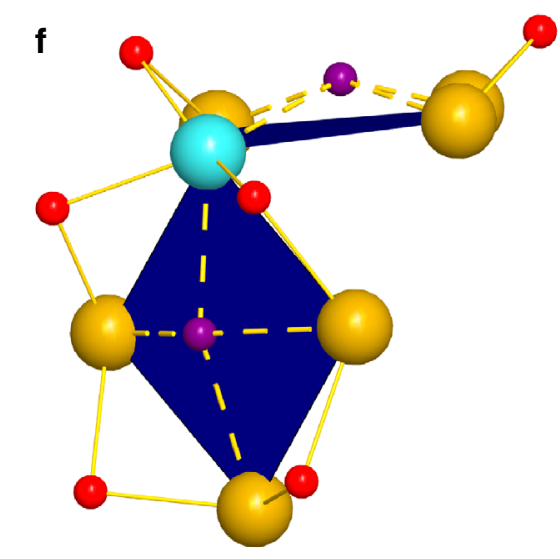

Fig. 3 Structural features on the surface of ceria nanoclusters. a $\mu_{3}-\mathrm{OH}^{-}$on (111) $\mathrm{Ce}^{\mathrm{IV}}$ triangle; $\mathbf{b} \mu_{4}-\mathrm{OH}^{-}$on a $(100) \mathrm{Ce}^{\mathrm{IV}}{ }_{4}$ square; $\mathbf{c} \mu_{4}-\mathrm{OH}^{-}$on a (100) $\mathrm{Ce}^{\mathrm{III}} \mathrm{Ce} \mathrm{e}_{3}^{\mathrm{IV}}$ square; $\mathbf{d} \eta^{2}$-carboxylates in $\mathbf{3} \mathbf{a}$ acting as lids on adjacent (100) $\mathrm{Ce} \mathrm{eV}_{4}$ and $\mathrm{Ce}{ }^{\mathrm{III}} \mathrm{Ce}^{\mathrm{IV}}{ }_{3}$ squares; $\mathbf{e}$ the analogous situation in $\mathbf{3} \mathbf{b}$ to that in $\mathbf{d}$, with an $\mathrm{MeCN}$ ligand replacing one $\eta^{2}$-carboxylate as lid; and $\mathbf{f} \mu_{4}-\mathrm{OH}^{-}$lids on a V-shaped (100) Ce ${ }^{I I I} \mathrm{Ce}{ }^{\mathrm{IV}}{ }_{3}$ double-square in $\mathbf{1}$ linked at the Ce $\mathrm{e}^{\text {III }}$ corner. Color code: $\mathrm{Ce}^{\mathrm{IV}}$ gold, $\mathrm{Ce} \mathrm{e}^{\text {III }}$ sky-blue, $\mathrm{O}$ red, $\mathrm{OH}^{-}$purple, $\mathrm{N}$ blue, $\mathrm{C}$ grey. $\mathrm{H}$ atoms have been omitted for clarity

attached to $\mathrm{Ce}^{3+}$, namely $\mathrm{O} 40, \mathrm{O} 40^{\prime}$ and $\mathrm{O} 83$, form a triangle and all show lowered BVS values of 1.78, 1.78 and 1.65, respectively, suggesting an $\mathrm{H}^{+}$is capping each of the two triangles in $\mathbf{3 a}$ by interacting with the $\mathrm{O}$ atoms in a trifurcated fashion (Supplementary Table 5). The formulation of $\mathbf{3 b}$ can now be rationalized as resulting from loss of some of the chelating $\mathrm{MeCO}_{2}{ }^{-}$groups in 3a, assisted by protonation to $\mathrm{MeCO}_{2} \mathrm{H}$ by these $\mathrm{H}^{+}$, and replacement by $\mathrm{MeCN}$ solvent molecules in $\mathbf{3 b}$.

The two $\mathrm{Ce}^{3+}$ each in $\mathbf{1}$ and $\mathbf{3}$ are thus all at surface sites, as suggested to also be the case in $\mathrm{CNPs}^{10,38}$. The lower $\mathrm{Ce}^{3+}$ charge favors fewer $\mathrm{O}^{2-}$ ligands than $\mathrm{Ce}^{4+}$ and thus disfavors body sites. In contrast, 2 contains no $\mathrm{Ce}^{3+}$. Interestingly, all $\mathrm{Ce}^{3+}$ occur within (100) $\mathrm{Ce}^{4+}{ }_{3} \mathrm{Ce}^{3+}$ square facets. In 3 (Fig. 3c), the $\mathrm{Ce}^{3+} . . \mathrm{OH}^{-}$and $\mathrm{Ce}^{4+} . . \mathrm{OH}^{-}$distances are identical $(\sim 2.7 \AA)$, again supporting weak contacts by the $\mu_{4}-\mathrm{OH}^{-}$. In $\mathbf{1}$, the $\mathrm{V}$-shaped double-square joined at the $\mathrm{Ce}^{3+}$ corner (Fig. 3f) has a $\mathrm{Ce}^{3+} . . \mathrm{OH}^{-}$distance of $\sim 2.7 \AA$ on one side, but this causes a longer $\mathrm{Ce}^{3+} . . \mathrm{OH}^{-}$on the other ( 3.0 $\AA$; Supplementary Table 7). It is also extremely interesting that when $\mathrm{Ce}^{3+}$ ions are present, the surface $\mathrm{H}^{+}$(i.e., $\mathrm{OH}^{-}$ions, and $\mathrm{H}^{+}$hydrogen bonding to carboxylate groups) are located very close to them. The presence and positions of $\mathrm{H}^{+}$on nanoparticles are extremely challenging to determine ${ }^{39}$, but in nanoclusters $\mathbf{1}$ and $\mathbf{3}$ most of them are directly observed and clearly accumulate on $\mathrm{O}$ atoms near $\mathrm{Ce}^{3+}$ (Fig. 1d, f). The effect is likely synergistic, i.e., the lower $\mathrm{Ce}^{3+}$ charge favors accumulation of $\mathrm{H}^{+}$nearby, which in turn mollify the $\mathrm{O}^{2-}$ and carboxylate charges and stabilize the lower $\mathrm{Ce}^{3+}$ charge. In contrast, with no $\mathrm{Ce}^{3+}$ in 2 , the $\mathrm{H}^{+}$spread out over the surface (Fig. 1e), although they again favor $\mathrm{Ce}_{4}$ squares. $\mathrm{H}^{+}$are expected to be mobile on the nanocluster surfaces, as recent work has concluded from studies of hydrogen mobility ('hopping') on surface $\mathrm{O}$ atoms of $\mathrm{CeO}_{2}$ thin films ${ }^{40}$. Double protonation of an $\mathrm{O}^{2-}$ and desorption of surface $\mathrm{H}_{2} \mathrm{O}$ was suggested as the means of forming $\mathrm{O}$ vacancies.

\section{Discussion}

We have shown that a bottom-up synthetic approach in solution at ambient temperatures using readily available reagents can be successfully applied to obtain a family of monodisperse metal oxide nanoparticles of ultra-small dimensions. This thus achieves for metal oxides what was previously accomplished for the distinctly different area of metal nanoparticles, particularly of Au. In the present work, monodisperse $\mathrm{CeO}_{2}$ nanoclusters with the fluorite structure and monolayer organic ligand shells can be synthesized and structurally characterized to atomic resolution. They exhibit multifaceted structures consisting mainly of (100) and (111) facets, but 3 also has (110) facets giving noticeable surface kinks/edges/trenches. The surface location of any $\mathrm{Ce}^{3+}$ ions and the $\mathrm{H}^{+}$positions on $\mu_{3^{-}}$and $\mu_{4}-\mathrm{OH}^{-}$groups, as well as ligand groups, are particularly welcome to know. The $\mu_{4}-\mathrm{OH}^{-}$are weakly attached with long $\mathrm{Ce} \cdots \mathrm{O}$ distances to the (100) facets, acting as lids on $\mathrm{Ce}_{4}$ squares, as also do $\mathrm{O}$ (carboxylate) and $\mathrm{N}$ (MeCN) lids on other (100) facets. Such surface features are likely of great relevance to CNP reactivity: Under heterogeneous catalysis conditions, or in solution or colloidal suspension, one can 
envisage the ready loss or 'opening' of such weakly interacting lids (e.g., by protonation of $\mathrm{OH}^{-}$, detachment of $\mathrm{MeCN}$, or tilting away of the chelating carboxylate, perhaps by becoming monodentate) exposing $\mathrm{Ce}_{4}$ square faces for reaction. We thus propose these weakly lidded $\mathrm{Ce}_{4}$ sites as resting states of some of the catalytically highly reactive, surface O-vacancy sites in CNPs. In addition, when $\mathrm{Ce}^{3+}$ ions are present, their locations in $\mathbf{1}$ and 3 corner-linking two (100) $\mathrm{Ce}^{3+} \mathrm{Ce}^{4+}{ }_{3}$ squares, and the concomitant accumulation nearby of mobile $\mathrm{H}^{+}$, on $\mu_{3}-\mathrm{OH}^{-}, \mu_{4}-\mathrm{OH}^{-}$and/or ligand groups, together offer a possible picture for the high catalytic activity of surface $\mathrm{Ce}^{3+}$ in CNPs. Similarly, the kinks/edges/ trenches associated with the (110) facets in $\mathbf{3}$ suggest additional sites of increased reactivity, as seen for (110) facets of CNPs, and they have also been identified in CNPs as nucleation sites for heterometals ${ }^{41,42}$, a process we are trying to mimic with 3 . We note that there is a general consensus that the (111) facet of CNPs is the most thermodynamically stable while the (100) facet is highly reactive due its lower stability and is therefore a proposed site for $\mathrm{O}$ vacancies and $\mathrm{Ce}^{3+}$ ions ${ }^{17,29,43}$, observations that are consistent with the surface features we have identified in 1-3.

Even on the basis of only the three nanoclusters described herein, it is already apparent how CNPs with similar sizes can have very different properties and reactivities. Although $\mathbf{2}$ and $\mathbf{3}$ are essentially the same size and metal nuclearity, they differ significantly in their overall shape, the variety of facets they exhibit, the resulting surface morphology, and their $\mathrm{Ce}^{3+}$ content. On the other hand, the availability now of samples of identical, monodisperse nanoclusters makes possible the study of activity vs. exact size, surface morphology and $\mathrm{Ce}^{3+}$ content. In addition, while dispersions of CNPs in water are often unstable, leading to agglomeration that can affect their transport, distribution and reactivity, particularly for ultra-small CNPs in biomedical studies, 3 is completely water soluble and affords the opportunity to study reactivity in biologically relevant media ${ }^{27,44}$.

Finally, 1-3 contain either $\mathrm{Ce}^{4+}{ }_{4}^{-} \mu_{4}-\mathrm{OH}^{-}$or $\mathrm{Ce}^{3+} \mathrm{Ce}^{4+}{ }_{3}^{-} \mu_{4^{-}}$ $\mathrm{OH}^{-}(100)$ squares, or both, and this variation may also be responsible for the recognized redox-state dependent ROSscavenging ability and toxicity of CNPs with different amounts of surface $\mathrm{Ce}^{3+21,22,45,46}$. In contrast, recent suggestions that 1.1-3.5 nm CNPs should have a defect-fluorite structure and a large surface $\mathrm{Ce}^{3+}: \mathrm{Ce}^{4+}$ ratio are not supported by $1-3^{47,48} \cdot \mathrm{Ce}^{3+}$ is certainly on the surface, but no correlation between size and the number of $\mathrm{Ce}^{3+}$ is seen, with $\mathrm{Ce}_{24}$ and $\mathrm{Ce}_{40}$ having two each, but $\mathrm{Ce}_{38}$ none. In fact, given that $\mathrm{Ce}^{3+}$ ions in 1-3 always occur at the centre of V-shaped double-square subunits (Fig. $3 \mathrm{f}$ and similar), we hypothesize that the higher symmetry, essentially spherical 2 contains no $\mathrm{Ce}^{3+}$ because its surface structure contains no such double squares. Furthermore, the conventional wisdom that smaller CNPs have more surface $\mathrm{Ce}^{3+}$ may reflect the greater number of such $\mathrm{V}$-shaped units present in smaller nanoparticles of lower symmetry as a result of their increased number of points of high curvature. We are currently seeking to extend the family to larger nanoclusters and higher $\mathrm{Ce}^{3+}: \mathrm{Ce}^{4+}$ ratios, and exploring the reactivity of $\mathbf{1 - 3}$ with ROS.

\section{Methods}

Syntheses. $\left[\mathrm{Ce}_{24} \mathrm{O}_{28}(\mathrm{OH})_{8}\left(\mathrm{PhCO}_{2}\right)_{30}(\mathrm{py})_{4}\right]$ (1) was prepared by the reaction of $\left(\mathrm{NH}_{4}\right)_{2}\left[\mathrm{Ce}\left(\mathrm{NO}_{3}\right)_{6}\right]$ and $\mathrm{PhCO}_{2} \mathrm{H}$ in a 1:2 molar ratio in pyridine at room temperature. The golden-yellow solution was stirred for 30 mins, diluted with 2 volumes of MeCN, and maintained undisturbed for 1 week. The resulting yellow square plates of 1.9 py were collected by filtration, washed with $\mathrm{MeCN}$, and dried in vacuum. The yield was $14 \%$ based on Ce. Anal. Calcd (Found) for dried 1.2py $\left(\mathrm{C}_{240} \mathrm{H}_{188} \mathrm{Ce}_{24} \mathrm{~N}_{6} \mathrm{O}_{96}\right)$ : C, 35.79 (35.63); $\mathrm{H}, 2.35$ (2.00); N, 1.04 (0.98).

$\left[\mathrm{Ce}_{38} \mathrm{O}_{54}(\mathrm{OH})_{8}\left(\mathrm{EtCO}_{2}\right)_{36}(\mathrm{py})_{8}\right](2)$ and $\left[\mathrm{Ce}_{40} \mathrm{O}_{56}(\mathrm{OH})_{2}\left(\mathrm{MeCO}_{2}\right)_{44}\left(\mathrm{MeCO}_{2} \mathrm{H}\right)_{2}\right.$ $\left.(\mathrm{py})_{4}\right] /\left[\mathrm{Ce}_{40} \mathrm{O}_{56}(\mathrm{OH})_{2}\left(\mathrm{MeCO}_{2}\right)_{44}(\mathrm{MeCN})_{2}(\mathrm{py})_{4}\right](\mathbf{3})$ were prepared by the reactionof $\left(\mathrm{NH}_{4}\right)_{2}\left[\mathrm{Ce}\left(\mathrm{NO}_{3}\right)_{6}\right]$, the corresponding $\mathrm{RCO}_{2} \mathrm{H}$, and $\mathrm{NH}_{4} \mathrm{I}$ in a 1:4:1 molar ratio in pyridine $/ \mathrm{H}_{2} \mathrm{O}(10: 1 \mathrm{v} / \mathrm{v})$ at room temperature. The golden-yellow solutions were stirred for $30 \mathrm{~min}$, diluted with two volumes of MeCN, and maintained undisturbed for 4 weeks. The resulting yellow square plates

$(2 \cdot 16 \mathrm{MeCN})$ or rods $(3 \cdot 48 \mathrm{MeCN})$ were collected by filtration, washed with $\mathrm{MeCN}$, and dried in vacuum. The yields were $49 \%$ and $35 \%$ for $\mathbf{2}$ and $\mathbf{3}$, respectively. Anal. Calcd (Found) for $2 \cdot 7 \mathrm{H}_{2} \mathrm{O}\left(\mathrm{C}_{148} \mathrm{H}_{242} \mathrm{Ce}_{38} \mathrm{~N}_{8} \mathrm{O}_{141}\right)$ : C, 18.30 (17.90); $\mathrm{H}, 2.51$ (2.36) $\mathrm{N}, 1.15$ (1.05). Anal. Calcd (Found) for $3 \cdot 8 \mathrm{H}_{2} \mathrm{O}\left(\mathrm{C}_{112} \mathrm{H}_{178} \mathrm{Ce}_{40} \mathrm{~N}_{5} \mathrm{O}_{156}\right)$ : C, 13.88 (13.79); H, 1.85 (1.78); $\mathrm{N}, 0.72$ (0.76). The indicated atomic composition of 3 is calculated using the average of the $\mathbf{3 a}$ and $\mathbf{3 b}$ formulas.

Fuller details of the three syntheses and infra-red spectral data for 1-3 are available in Supplementary Methods.

X-ray crystallography. Single-crystal X-ray diffraction studies at $-173^{\circ} \mathrm{C}$ were performed on a Bruker DUO diffractometer using $\operatorname{MoK}_{\alpha}(\lambda=0.71073 \AA)$ or $\mathrm{CuK}_{\alpha}$ $(\lambda=1.54178 \AA$ ) radiation (from an ImuS power source), and an APEXII CCD area detector (Supplementary Methods and Supplementary Table 1). The metric parameters of the refined structures were used to determine the Ce oxidation states and the $\mathrm{O}$ protonation levels by bond valence sum (BVS) calculations (Supplementary Tables $2-5$ ).

Data availability. The crystallographic information files (CIFs) for $\left[\mathrm{Ce}_{24} \mathrm{O}_{28}(\mathrm{OH})_{8}\left(\mathrm{PhCO}_{2}\right)_{30}(\text { py })_{4}\right] \cdot 9$ py $\left(1 \bullet 9\right.$ py), $\left[\mathrm{Ce}_{38} \mathrm{O}_{54}(\mathrm{OH})_{8}\left(\mathrm{EtCO}_{2}\right)_{36}(\mathrm{py})_{8}\right]$ -16MeCN $(2 \cdot 16 \mathrm{MeCN})$, and $\left[\mathrm{Ce}_{40} \mathrm{O}_{56}(\mathrm{OH})_{2}\left(\mathrm{MeCO}_{2}\right)_{44}\left(\mathrm{MeCO}_{2} \mathrm{H}\right)_{2 / 0}(\mathrm{MeCN})_{0 / 2}\right.$ (py) ${ }_{4} \cdot 48 \mathrm{MeCN}(3 \cdot 48 \mathrm{MeCN})$ have been deposited at the Cambridge Crystallographic Data Centre with deposition codes CCDC 1529955-1529957 for 1-3, respectively.

Received: 9 August 2017 Accepted: 6 October 2017 Published online: 13 November 2017

\section{References}

1. Flytzani-Stephanopoulos, M. Nanostructured cerium oxide "ecocatalysts". MRS. Bull. 26, 885-889 (2001).

2. Trovarelli, A. Catalytic properties of ceria and $\mathrm{CeO} 2$-containing materials. Catal. Rev. 38, 439-520 (1996).

3. Wang, Q., Zhao, B., Li, G. \& Zhou, R. Application of rare earth modified $\mathrm{Zr}$-based ceria-zirconia solid solution in three-way catalyst for automotive emission control. Environ. Sci. Technol. 44, 3870-3875 (2010).

4. Qi, X. M. \& Flytzani-Stephanopoulos, M. Activity and Stability of $\mathrm{Cu}-\mathrm{CeO} 2$ Catalysts in high-temperature water-gas shift for fuel-cell applications. Ind. Eng. Chem. Res. 43, 3055-3062 (2004).

5. Sharma, S., Hilaire, S., Vohs, J. M., Gorte, R. J. \& Jen, H. W. Evidence for oxidation of ceria by $\mathrm{CO}_{2}$. J. Catal. 190, 199-204 (2000).

6. Murray, E. P., Tsai, T. \& Barnett, S. A. A direct-methane fuel cell with a ceria-based anode. Nature 400, 649-651 (1999).

7. Panagiotopoulou, P., Papavasiliou, J., Avgouropoulos, G., Ioannides, T. \& Kondarides, D. I. Water-gas shift activity of doped $\mathrm{Pt} / \mathrm{CeO} 2$ catalysts. Chem. Eng. J. 134, 16-22 (2007)

8. Fan, L., Wang, C., Chen, M. \& Zhu, B. Recent development of ceria-based (nano)composite materials for low temperature ceramic fuel cells and electrolyte-free fuel cells. J. Power Sources 234, 154-174 (2013).

9. Sun, C., Li, H. \& Chen, L. Nanostructured ceria-based materials: synthesis, properties, and applications. Energy Environ. Sci. 5, 8475-8505 (2012).

10. Reed, K. et al. Exploring the properties and applications of nanoceria: is there still plenty of room at the bottom? Environ. Sci. Nano 1, 390-405 (2014).

11. Castano, C. E., O’Keefe, M. J. \& Fahrenholtz, W. G. Cerium-based oxide coatings. Curr. Opin. Solid State Mater. Sci 19, 69-76 (2015).

12. Perullini, M., Aldabe Bilmes, S. A. \& Jobbagy, M. in Nanomaterials: A Danger or a Promise? (eds Brayner, R., Fiévet, F. \& Coradin, T.) 307-333 (Springer, London, 2012).

13. Beckers, J. \& Rothenberg, G. Sustainable selective oxidations using ceria-based materials. Green. Chem. 12, 939-948 (2010).

14. Lawrence, N. J. et al. Defect engineering in cubic cerium oxide nanostructures for catalytic oxidation. Nano Lett. 11, 2666-2671 (2011).

15. Tabakova, T. et al. A comparative study of nanosized IB/ceria catalysts for low-temperature water-gas shift reaction. Appl. Catal. A 298, 127-143 (2006).

16. Mann, A. K. P., Wu, Z., Calaza, F. C. \& Overbury, S. H. Adsorption and reaction of acetaldehyde on shape-controlled $\mathrm{CeO}_{2}$ nanocrystals: elucidation of structure-function relationships. ACS Catal 4, 2437-2448 (2014).

17. Zhang, J. et al. Extra-low-temperature oxygen storage capacity of $\mathrm{CeO}_{2}$ nanocrystals with cubic facets. Nano Lett. 11, 361-364 (2011).

18. Corma, A., Atienzar, P., Garcia, H. \& Chane-Ching, J.-Y. Hierarchically mesostructured doped $\mathrm{CeO}_{2}$ with potential for solar-cell use. Nat. Mater. 3, 394-397 (2004). 
19. Carrettin, S., Concepción, P., Corma, A., López Nieto, J. M. \& Puntes, V. F. Nanocrystalline $\mathrm{CeO}_{2}$ increases the activity of $\mathrm{Au}$ for $\mathrm{CO}$ oxidation by two orders of magnitude. Angew. Chem. Int. Ed. 43, 2538-2540 (2004).

20. Lee, S. S. et al. Antioxidant properties of cerium oxide nanocrystals as a function of nanocrystal diameter and surface coating. ACS Nano 7, 9693-9703 (2013).

21. Das, S. et al. Cerium oxide nanoparticles: applications and prospects in nanomedicine. Nanomedicine 8, 1483-1508 (2013)

22. Xu, C. \& Qu, X. Cerium oxide nanoparticle: a remarkably versatile rare earth nanomaterial for biological applications. NPG Asia Mater. 6, e90 (2014).

23. Aubriet, F. et al. Cerium oxyhydroxide clusters: Formation, structure, and reactivity. J. Phys. Chem. A 113, 6239-6252 (2009).

24. Baer, D. R. et al. Surface characterization of nanomaterials and nanoparticles: Important needs and challenging opportunities. J. Vac. Sci. Technol. A 31, 050820 (2013).

25. Jadzinsky, P. D., Calero, G., Ackerson, C. J., Bushnell, D. A. \& Kornberg, R. D. Structure of a thiol monolayer-protected gold nanoparticle at $1.1 \AA$ resolution. Science 318, 430-433 (2007).

26. Jin, R., Zeng, C., Zhou, M. \& Chen, Y. Atomically precise colloidal metal nanoclusters and nanoparticles: fundamentals and opportunities. Chem. Rev. 116, 10346-10413 (2016).

27. Grulke, E. et al. Nanoceria: factors affecting its pro- and anti-oxidant properties. Environ. Sci. Nano 1, 429-444 (2014).

28. Bruix, A. \& Neyman, K. M. Modeling ceria-based nanomaterials for catalysis and related applications. Catal. Lett. 146, 2053-2080 (2016).

29. Preda, G. et al. Formation of superoxide anions on ceria nanoparticles by interaction of molecular oxygen with $\mathrm{Ce}^{3+}$ sites. J. Phys. Chem. C 115, 5817-5822 (2011).

30. Dutta, $\mathrm{P}$. et al. Concentration of $\mathrm{Ce}^{3+}$ and oxygen vacancies in cerium oxide nanoparticles. Chem. Mater. 18, 5144-5146 (2006).

31. Canevali, C. et al. Stability of luminescent trivalent cerium in silica host glasses modified by boron and phosphorus. J. Am. Chem. Soc. 127, 14681-14691 (2005).

32. Martos, M., Julián-López, B., Folgado, J. V., Cordoncillo, E. \& Escribano, P. Sol-Gel synthesis of tunable cerium titanate materials. Eur. J. Inorg. Chem. 2008, 3163-3171 (2008).

33. Chen, J., Patil, S., Seal, S. \& McGinnis, J. F. Rare earth nanoparticles prevent retinal degeneration induced by intracellular peroxides. Nat. Nano 1, 142-150 (2006).

34. Ju-Nam, Y. \& Lead, J. R. Manufactured nanoparticles: An overview of their chemistry, interactions and potential environmental implications. Sci. Total Environ. 400, 396-414 (2008)

35. Mathey, L., Paul, M., Copéret, C., Tsurugi, H. \& Mashima, K. Cerium(IV) hexanuclear clusters from cerium(III) precursors: Molecular models for oxidative growth of ceria nanoparticles. Chem. Eur. J. 21, 13454-13461 (2015).

36. Estes, S. L., Antonio, M. R. \& Soderholm, L. Tetravalent Ce in the nitratedecorated hexanuclear cluster $\left[\mathrm{Ce}_{6}\left(\mu_{3}-\mathrm{O}\right)_{4}\left(\mu_{3}-\mathrm{OH}\right)_{4}\right]^{12+}$ : A structural end point for ceria nanoparticles. J. Phys. Chem. C 120, 5810-5818 (2016).

37. Malaestean, I. L., Ellern, A., Baca, S. \& Kogerler, P. Cerium oxide nanoclusters: commensurate with concepts of polyoxometalate chemistry? Chem. Commun. 48, 1499-1501 (2011).

38. Loschen, C., Bromley, S. T., Neyman, K. M. \& Illas, F. Understanding ceria nanoparticles from first-principles calculations. J. Phys. Chem. C 111, 10142-10145 (2007)

39. Zherebetskyy, D. et al. Hydroxylation of the surface of PbS nanocrystals passivated with oleic acid. Science 344, 1380-1384 (2014).

40. Shahed, S. M. F. et al. STM and XPS study of $\mathrm{CeO} 2(111)$ reduction by atomic hydrogen. Surf. Sci 628, 30-35 (2014).
41. Lu, J. L., Gao, H. J., Shaikhutdinov, S. \& Freund, H. J. Gold supported on wellordered ceria films: nucleation, growth and morphology in CO oxidation reaction. Catal. Lett. 114, 8-16 (2007).

42. Nilius, N. et al. Formation of one-dimensional electronic states along the step edges of CeO2(111). ACS Nano 6, 1126-1133 (2012).

43. Mullins, D. R. The surface chemistry of cerium oxide. Surf. Sci. Rep. 70, 42-85 (2014).

44. Karakoti, A. S. et al. Nanoceria as antioxidant: synthesis and biomedical applications. JOM 60, 33-37 (2008).

45. Pulido-Reyes, G. et al. Untangling the biological effects of cerium oxide nanoparticles: the role of surface valence states. Sci. Rep 5, 15613 (2015).

46. Pirmohamed, T. et al. Nanoceria exhibit redox state-dependent catalase mimetic activity. Chem. Commun. 46, 2736-2738 (2010).

47. Hailstone, R. K., DiFrancesco, A. G., Leong, J. G., Allston, T. D. \& Reed, K. J. A study of lattice expansion in $\mathrm{CeO}_{2}$ nanoparticles by transmission electron microscopy. J. Phys. Chem. C. 113, 15155-15159 (2009).

48. Baranchikov, A. E., Polezhaeva, O. S., Ivanov, V. K. \& Tretyakov, Y. D. Lattice expansion and oxygen non-stoichiometry of nanocrystalline ceria. Cryst. Eng. Commun. 12, 3531-3533 (2010).

\section{Acknowledgements}

This work was supported by the Drago Endowment and the University of Florida. K.A.A thanks UF and NSF grant CHE-0821346 for funding the purchase of X-ray equipment. We thank J. Goodsell for his assistance with the EPR measurements.

\section{Author contributions}

K.J.M. carried out all the syntheses and characterizations, and co-wrote the paper. K.A.A. performed the single-crystal X-ray diffractometry studies. G.C. supervised the research and co-wrote the paper.

\section{Additional information}

Supplementary Information accompanies this paper at doi:10.1038/s41467-017-01672-4.

Competing interests: The authors declare no competing financial interests.

Reprints and permission information is available online at http://npg.nature.com/ reprintsandpermissions/

Publisher's note: Springer Nature remains neutral with regard to jurisdictional claims in published maps and institutional affiliations.

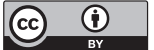

Open Access This article is licensed under a Creative Commons Attribution 4.0 International License, which permits use, sharing, adaptation, distribution and reproduction in any medium or format, as long as you give appropriate credit to the original author(s) and the source, provide a link to the Creative Commons license, and indicate if changes were made. The images or other third party material in this article are included in the article's Creative Commons license, unless indicated otherwise in a credit line to the material. If material is not included in the article's Creative Commons license and your intended use is not permitted by statutory regulation or exceeds the permitted use, you will need to obtain permission directly from the copyright holder. To view a copy of this license, visit http://creativecommons.org/ licenses/by/4.0/.

(C) The Author(s) 2017 